\title{
Regulated and Unregulated Clinical Trials of Stem Cell Therapies for Stroke
}

\author{
Michael G. Liska ${ }^{1}$ - Marci G. Crowley ${ }^{1}$ - Cesar V. Borlongan ${ }^{1}$
}

Received: 14 January 2017 / Accepted: 17 January 2017 / Published online: 26 January 2017

(C) Springer Science+Business Media New York 2017

\section{Introduction}

Stem cell therapies have been demonstrated in the laboratory as an effective option in treating a number of neurological disorders, including stroke. By targeting the subacute and chronic phases of stroke, stem cell therapies offer the advantage of extending the intervention window which has traditionally been oppressively small. Although substantial laboratory data support this therapeutic potential, transitioning stem cell treatments into approved clinical products has proven difficult. The reasons for this are many, including fundamental complications which have accompanied non-traditional pharmaceuticals such as difficulties in achieving treatment/dosing/ cell type consensus and also the regulatory and legislative hindrances which have plagued stem cell advancement. Fortunately, translational lab-to-clinic research endeavors are being made in all of the abovementioned categories, allowing the initiation of limited clinical trials of stem cell therapies for stroke patients.

Our understanding of stem cell types and their varying sources has been instrumental in furthering the field. Specifically, investigations revealing the bioavailability and stemness capacity of different adult tissue sources - including bone marrow-derived, blood-derived, and adipose-derivedhave guided current research efforts. These cell types have circumvented the need for fetal and embryonic stem cells, thus allowing the field to avoid some of the ethical and logistical

Cesar V. Borlongan

cborlong@health.usf.edu

1 Center of Excellence for Aging and Brain Repair, Department of Neurosurgery and Brain Repair, University of South Florida Morsani College of Medicine, 12901 Bruce B. Downs Blvd,

Tampa, FL 33612, USA obstacles which have severely delayed research in the past. Additionally, a rising awareness of the importance of basic science-inspired clinical trial designs has been and will continue to be crucial in the development of successful trials.

To date, multiple clinical trials examining the efficacy of stem cell therapies in stroke are currently under way. These clinical trials have reliably displayed the safety of finely regulated stem cell therapies, yet demonstrating their efficacy has proved less consistent - in large part due to small patient enrolment. This lack of demonstration of efficacy in stroke patients (and patients with other neurologic disorders) has left an unmet demand for stem cell therapies. Unregulated and experimental stem cell clinics have risen to fill this demand as a result of the delayed transition from the laboratory to the clinic and the "cure-all" promise of stem cells which has been circulated by the media. These scrupulous stem cell clinics operate under minimal oversight in many instances and pose a danger to patients, as well as the stem cell field as a whole. This article will discuss the current state of stem cell research and clinical trials before addressing the dangers which unregulated stem cell therapies present. Finally, practical solutions will be presented for the challenges which are hindering the advancement of stem cell therapies into the clinic for patients suffering from stroke.

\section{Stem Cell Biology and Therapy}

Research into regenerative medicine has advanced the concept of stem cells as effective means of restoring central nervous system (CNS) function in the aging and diseased brain $[1,2]$. To date, numerous neurological disorders have been the subject of examination for stem cell therapy, with highly encouraging results alluding to its efficacy as a stroke treatment [3-5]. The current availability of a single stroke treatmentthrombolytic agent tissue plasminogen activator (tPA) - has 
not slowed the disease from being a major cause of mortality and morbidity. This is primarily due to tPA for possessing a narrowing therapeutic window and adverse side effects. By targeting the subacute and chronic phases of stroke, stem cells significantly extend the effective period of intervention, permitting a larger patient population to benefit from this prospective treatment. From the many cell types which have been transplanted in the laboratory, a small fraction have reached clinical trials for cell therapy in stroke, including fetal cells, NT2N cells, CTX0E3, embryonic stem cells, neural stem/ progenitor cells, umbilical cord blood, amnion, adipose, and induced pluripotent stem cells [6-10]. Bone marrow-derived cells have been distinguished in preclinical studies and ongoing clinical trials largely due to maintaining a consistent safety profile when used in other diseases [11, 12]. Additionally, functional benefits have been demonstrated via both intracerebral implantation and peripheral transplantation routes, such as intravenous, intra-arterial, and intranasal administration [11-15]. From the clinical trials which have been initiated and their preliminary reports, the safety of cell transplantation has generally been agreed upon, yet the efficacy warrants additional research [12].

When considering the multiple factors which affect cell transplantation - such as cell route, dose, and timing of administration - the specific stem cell type used is particularly important to treatment outcomes [16, 17]. Since the initial stroke animal studies with fetal cell transplantation, varying degrees of histological and behavioral improvement have been demonstrated following treatment with NT2N, CTX0E3, embryonic stem cells, hematopoietic stem cells, neural stem cells, adult tissue-derived stem cells, and induced pluripotent stem cells $[6-9,18]$. The quest for finding the optimal cell type for transplantation therapy has largely revolved around ethical and logistical issues [19]. Fetal and embryonic cells in particular have been laden with ethical concerns pertaining to their isolation, while the collection of a sufficient supply of cells that recapitulate "stemness" has been a logistical challenge for the other cell types. In addition to the consistent safety profile mentioned above, bone marrow-derived stem cells have emerged as a preeminent transplantable cell type for CNS disorders such as stroke due to being of adult tissue origin and bearing resemblance with many important stem cell phenotypic features [20]. Specialized subpopulations and bioengineered stem/proge nitor cells have been derived and procured from bone marrow, including mesenchymal stem cells (MSCs) or stromal cells, endothelial progenitor cells (EPCs), SB623, multipotent adult progenitor cells (MAPCs), multilineage-differentiating stress enduring (Muse), and others [21-25]. Among these bone marrow-derived cells, MSCs have been extensively investigated in stroke animal models. MSCs display adult multipotency characteristics, maintaining the ability to differentiate towards several cell lineages both in vitro and in vivo
[11, 26-30]. Following their transplantation in stroke models, MSCs promoted functional recovery evident by a reduction in cerebral tissue damage and improvements in motor and cognitive performance [31].

Proposed mechanisms of action for stem cells are numerous, including cell replacement, growth factor secretion, inflammation sequestration, and promotion of endogenous brain repair processes (including neurogenesis, angiogenesis, and synaptogenesis) - all triggered directly by the grafted MSCs or by their secretions [22, 32-35]. Despite stem cells being characterized as biologics, evaluation of their early clinical applications reveals an initial influence of the ligand-receptor pharmacology usually ascribed to drugs. In line with this, a reductionist singular regenerative pathway prevailed in the quest to define the mode of action responsible for the therapeutic effects seen in the stroke brain. Fortunately, we now appreciate the multipronged nature of regenerative stem cell therapy, complimenting very well the numerous cell death processes that plague stroke brains [36-38]. The complexity of stroke physiopathology may also necessitate combination therapy options, including potent drugs and biomaterials, which may synergistically facilitate improved functional outcomes of stem cell-based therapies in stroke patients.

\section{Stem Cell Therapy Clinical Trials}

Clinical trials of stem cell therapy for stroke typically fall within two categories, namely peripheral delivery treatments in subacute stroke patients or intracerebral transplantation for chronic stroke patients. Initially, for safety purposes, autologous transplantation of bone marrow-derived stem cells was the first treatment to reach the clinic, and this included trials of minimally invasive delivery routes that utilized intravenous [39-41] and intra-arterial [42] routes in subacute stroke patients. While preclinical studies of intracerebral transplantation began before exploring peripheral administration methods, the regulatory requirements for direct transplantation present a greater challenge due to its invasive nature and its target of chronic patients; therefore, direct transplantation has taken a slower path towards clinical application [12, 43]. Apparent in these clinical trials is the preference for bone marrow-derived MSCs as the graft source. Additionally, MSCs and fetal brain-derived neuronal cells have been genetically engineered to obtain a homogenous cell population for transplantation. As preliminary results from on-going clinical trials are publicized, prudent evaluation is required for an accurate evaluation of the improvements observed in patients, thus progressing stem cells as the future of regenerative medicine for neurological disorders such as stroke. 


\section{Peripheral Injection in Subacute Stroke}

Autologous MSCs received regulatory approval for rapid entry into clinical trials. One particular study evaluated autologous intravenous bone marrow transplantation (dose of 7-10 million mononuclear cells (MNCs) per kilogram) 24 and $72 \mathrm{~h}$ after stroke (subacute). Over a 6-month period, this open-labeled study resulted in significant clinical improvements evaluated with a modified Rankin scale and with no adverse effects observed or reported [44]. The proceeding phase II included 58 patients at median of 18.5 days post-stroke administered an average of 280.75 million cells. In this multicenter randomized trial, there were no improvements in the modified Rankin scale shift analysis, National Institutes of Health Stroke Scale (NIHSS) score, or the Barthel index score [13]. In addition, no significant decreases in infarct volume were detected 6 months post-transplantation when compared to non-transplanted stroke patients [13]. Based on these results, while passing safety standards, intravenous transplantation of MNCs in subacute stroke was not indicated to be effective.

Another study evaluated the use of immunoselected $\mathrm{CD} 34+$ bone marrow MNCs with intra-arterial delivery in 5 stroke patients within 7 days of onset, each diagnosed with severe anterior circulation ischemic stroke (NIHSS score of $\geq 8$ ) [45]. During a 6-month follow-up period, no adverse events were reported and both reductions in lesion volume and improved modified Rankin scale and NIHSS scores were observed.

In a study exploring delayed treatment of stroke, 50 million MSCs were administered intravenously at 4 weeks after onset followed by another injection at 6 weeks. This study included 16 stroke patients and resulted in improved neurological effects evaluated with the modified Rankin scale, as wells as the absence of serious side effects over a 5-year follow-up period [46].

\section{Direct Stem Cell Implantation in Chronic Stroke}

Recent clinical trials have explored the use of genetically modified stem cells as a treatment for chronic stroke [12, 43] as recently reviewed [5]. The CTX-DP neuronal cell line originated from human fetal brain was utilized in the UK-based ReNeuron Phase 1 trial called PISCES [43], whereas SB623, bone marrow-derived MSCs, were used in the US-based SanBio, Inc., Phase 1/2A trial called ACTIsSIMA [6].

The PISCES trial included 11 men who had suffered ischemic stroke and were aged 60 years or older with stable disability based on NIHSS score $\geq 6$ and modified Rankin Scale score of 2-4 [43]. This trial utilized CTX-DP cells 660 months following ischemic stroke via stereotactic putaminal transplantation [43]. Some improvements in functional and neurological outcomes were observed 24 months post-transplantation (single intracerebral doses $2-20 \times 10^{6}$
CTX-DP cells) with no adverse effects from the transplanted cells. In the ACTIsSIMA trial, 18 chronic stroke patients were evaluated 12 months post-transplantation and data showed that some transplanted patients exhibited significant improvements from baseline (average increase of $>19$ in Fugl-Meyer total score, mean surge of $>11$ in Fugl-Meyer motor function total score average rise of nearly 7 in the European Stroke Scale, and average decline of 2 in NIHSS) coupled with brain imaging suggesting tissue recovery readouts [12]. However, given the small sample size in both PISCES and ACTIsSIMA trials, it is hard to determine the efficacy of these cell therapies in stroke.

Reneuron utilized c-mycER (TAM) technology to attain conditional growth control with a fusion protein containing a growth promoting gene, c-myc, and a hormone receptor regulated by the synthetic drug, 4-hydroxy-tamoxifen (4-OHT) in generating CTX-DP immortalized cell line derived from first trimester human fetal cortical cells [47]. SanBio transfected human bone marrow-derived MSCs with a Notch intracellular domain (NICD)-expressing plasmid to generate SB623 cells which possess strong neural characteristics [47]. In contrast to the unmanipulated or minimally manipulated control MSCs, both genetically modified CTX-DP and SB623 cells, while being comprised of highly homogenous cell population, were slower to achieve clinical approval, in part because the gene therapy trials had resulted in the deaths of a number of participants [48]. Accordingly, while CTX-DP and SB623 passed the homogenous population litmus test, the enthusiasm for gene-modified stem cell products demanded more rigorous regulatory oversights. In reaction, long-term animal modeling studies were mandated by both the UK Regulatory and US FDA to establish the safety, efficacy, and mechanisms of transplanted CTX-DP and SB623 cells [6, 23]. Critical safety analyses including the silencing or gene insert deletion into CTX-DP and SB623 cells, respectively, before transplantation was a significant hurdle for gaining regulatory approval. Silencing of c-mycERTAM transgene was achieved in CTXDP after growth arrest (epidermal growth factor, basic fibroblast growth factor, and 4-OHT withdrawal) in cell culture, while CpG-island methylation was revealed to be the transgene silencing machinery following intracerebral implantation into stroke models [49]. For SB623, temporary NICD transfection barred the transfected plasmid from being expressed in daughter cells [50].

This dual approach of gene-amplified homogenization and gene silencing/restriction debatably altered the stemness and functional properties of CTX-DP and SB623. Specifically, the capacity of these neuronal-like cells to migrate is likely reduced due to the cell's lineage commitment being relegated to a neuronal phenotype only. Consequently, the transplant treatment was controlled by the limitation of the final stem cell product with little regard to the responsiveness of the stroke patient; to circumvent the lessened migratory potential 
of CTX-DP and SB623, trials were required to favor an invasive intracerebral transplant approach - a considerable burden to place on patients suffering from a debilitating brain disorder. Moreover, while the intracerebral approach necessitated a lower effective dose range of transplantable cells compared to peripheral routes, the initial targeted patient population consisted of severe stroke patients. While this is generally the case for early phase regulatory-approved invasive therapy clinical trials of this sort, critically ill patients undoubtedly mandate much higher cell count thresholds for effective outcomes.

\section{Considerations for Enhancing the Outcomes of Clinical Trials - Past, Present, and Future}

Clinical trials of cell therapy in subacute stroke have demonstrated the safety of transplanting MSCs and their cellular derivatives (including MNCs) in patients. In contrast, primarily due to small patient samples and an open-labeled approach, the efficacy of such treatments is still controversial. Additionally, inconsistent transplant regimens of the four peripheral transplantation protocols prevent vis-à-vis analysis of trial outcomes [51]. Similarly, cell dose, timing, and delivery route differ greatly across trials. The disconnect between laboratory findings and clinical transplant protocols calls into questions whether current clinical procedures are truly based on the robust scientific foundation needed to qualify as evidence-based medicine [52]. Furthermore, distinct donor cells were used in the trials, perhaps accounting for the varied clinical results. Based solely on this donor starting material, assessment of the four trial's outcomes will be inconclusive. Importantly, improved clinical design may be achieved by heeding the lab-to-clinic guidelines outlines by the Stem cell Therapeutics as an Emerging Paradigm for Stroke (STEPS) [16], likely improving functional outcomes of cell therapy for stroke.

Considering the data from the two clinical trials of cell therapy in chronic stroke, CTX-DP and SB623 cells genetically modified profile necessitate long-term monitoring of transplanted patients; despite solid gene silencing and restriction machinery being employed, the non-tumorigenic propensity of these cell types was only demonstrated in experimental stroke animals. In theory, the possibility exists that tumor or ectopic tissue formation could result from an amplified cmycERTAM transgene expression or stable transfection of NICD activating oncogenes when human CTX-DP or SB623 cells are transplanted in stroke patients.

As future clinical trials advance with larger patient samples, long-term follow-ups, and thorough assessment of the transplanted cells, we will be able to better analyze the safety, efficacy, and mechanisms of stem cell therapy for stroke patients. In this regard, to gain a fuller understanding of the target patient population, clinical trials utilizing peripheral transplantation of MSCs in subacute stroke and the CTX-DP and SB623 intracerebral transplants in chronic stroke should also be evaluated in a vis-à-vis fashion-taking into account the starting condition of the stroke patients and universalizing transplant protocols. Finally, this should be coupled with bench-to-bedside preclinical studies to produce ideal regimes for stem cell transplant in stroke patients.

\section{Unregulated Clinical Stem Cell Procedures}

The entry of stem cell therapy to the clinic as a treatment warrants a measure of realistic hope. For those suffering from a debilitating neurological disorder - such as stroke, traumatic brain injury, or neurodegenerative diseases - the prospect of stem cell therapy is an attainable goal and may become a reality in the foreseeable future. This hope has arisen from legitimate and relevant scientific discoveries, from the cells' initial embryonic characterization, to the revelation of the inducible nature of stem cells [53]. Indeed, stem cells have brought into fruition a novel field of medical research, regenerative medicine, which even through its namesake provokes hope. Unfortunately, distinguishing this hope from the unsubstantiated hype poses a pertinent challenge. This therapeutic hype has been nurtured by widespread patient misunderstanding and systematic misinformation [54]; the inconclusive data of stem cell clinical trials has not prevented their advertisement in the media as a "magic bullet," purported to have application in a myriad of pathological and aesthetic conditions. While stem cells indisputably hold relevance in many disorders, insufficient scientific data exist to support their safe and ethical use on a gross scale. Of great concern to the scientific community, this hype of stem cell therapy is being exploited in unregulated, highly experimental clinics around the world [55]. A culture which is largely naïve to the intricacies of cell therapy research - paired with the lure of financial gain from the commercialization of stem cells - has resulted in a dangerous medical environment which not only puts patient safety at risk but also hinders the progression of valid scientific research [56].

\section{FDA Regulations as Key Guiding Factor for Lab-to-Clinic Translation of Stem Cell Therapy}

Cell therapy has offered clinical promise since the late 1980s, yet their translation into effective clinical therapies has been undeniably slow. A number of factors have contributed to this, particularly the inherent complexity of stem cells and their dynamic interactions within the mammalian body. Additionally, legislative and bureaucratic elements have further slowed the pace of cell therapy advancement. The Federal 
Drug Administration (FDA) contributes to this discussion in the USA on two fronts - for one, certain policy shortcomings implemented by the FDA have inadvertently aided the rise of US stem cell clinics offering unproven treatments [57]. Secondly, other more stringent FDA regulations have served as a bottleneck for clinical advancements. Specifically, an understandable preoccupation with patient safety has nurtured a culture of safe but not effective treatments. This pattern of insufficient regulation over experimental clinics but deterring regulation over clinical research is not unique to the USA (as will be discussed shortly). Importantly, the two phenomena are connected; the rise of stem cell clinics has paralleled the slow progression of stem cell research, as patients pursue alternative options to the "behind schedule" approved stem cell therapies.

While stem cell clinics in the USA do fall under the regulatory guidance of the FDA, the advent of unregulated clinics is a product of the numerous legislative loopholes, ambiguities, and operational inadequacies which allow these clinics to carry out unproven treatment plans. This has permitted an estimated 570 clinics to open and operate within the USA to date [58]. Current guidelines dictate that cell therapy clinics properly prepare and store their therapeutics, as well as be subject to sporadic evaluations [58]. However, it is generally accepted that few, if any, unexpected visits are routinely made by the FDA. Additionally, cell therapy clinics need not receive regulatory approval for their treatments if the cells used are "minimally manipulated," retain homogenous properties and functions similar to those exhibited in the human body, and are not combined with other therapeutics [57, 58]. It is not difficult to see how the vagueness in such language could be exploited, especially when considering the minimal oversight mentioned above. Companies such as CellTex Therapeuticsa Texas-based company which offers stem cell treatmentshave exemplified the faults in the current system [59]. CellTex was able to register with and tout FDA compliance while circumventing key regulations by adhering more closely to state rules [59]. With hopes of harboring a productive industry, Texas has been legislatively accommodating to the growing stem cell industry, enabling CellTex to establish a market [59]. In addition, defining stem cell treatment to be a tissue transplant as opposed to a traditional drug allowed for more liberal use and fewer FDA restrictions [59].

On the other hand, cell therapies which do adhere to the traditional process of undergoing clinical trials often face harsh FDA oversight and must meet exceedingly high safety qualifications. Not only are the current FDA regulations of cell therapy trials stringent, but as efforts are made to tighten the reins on cell therapy clinics, it is possible that future legislation will advertently make the process even more difficult for researchers and physicians to move effective cell therapy into the clinic. Thus, it is imperative that a cognizant balance be reached, whereby the practices of dangerous and experimental clinics are prevented, but the means employed to do this not interfere with the translation of future legitimate stem cell therapies into the clinic.

\section{Medical Tourism}

The lack of FDA-approved, affordable, and accessible stem cell therapies in the USA has promoted a rising trend of medical tourism. Medical tourism involves patients traveling internationally to receive the proposed stem cell cure which is unavailable to them in their residential country [60], but it appears now that here in the USA, a patient may not need to travel abroad but just to a neighboring state to receive unregulated stem cell therapy. Nonetheless, the propagation of medical tourism has been aided by the ease in establishing international stem cell clinics, especially in countries with practically no regulatory oversight [61]. These clinics benefit from the hype and anecdotal evidence which surround stem cells, leading to patients accepting substantial costs for unproven treatments. The majority of patients who travel in search of stem cell therapies are suffering from a life-threatening or debilitating disease and therefore are willing to go to these extreme lengths in search for a cure. Australia, for one, has seen an increase in the number of stem cell clinics offering treatment for conditions ranging from multiple sclerosis and neurodegeneration to autism and "facial rejuvenation" [61]. Australia's regulatory Therapeutic Goods Administration regulates the use of cellular products but has excluded autologous cell use, leaving this entire medical industry without oversight [61]. Other nations around the world, including India, Japan, Turkey, and Canada exhibit similar patterns of hosting minimally regulated clinics which offer enticing, yet scientifically non-validated claims, of treating disease with stem cell therapies.

China is recognized as a focal point for the unregulated stem cell clinic industry. Due to clear ethical conflicts, the Chinese government attempted to ban these clinics, yet following the ban, there remained an estimated 100 stem cell clinics in the country in 2009 [62]. In fact, despite the ban, China's stem cell clinic industry continued to grow [62]. Fortunately, it appears that the standard maybe changing in China, with draft legislation issued in 2015 clearly attempting to correct China's wayward stem cell practices [63]. The new preliminary legislation dictates that any clinical use of stem cell therapies must pass through the rigorous evaluation similar to traditional pharmaceuticals in compliance with the Chinese Federal Drug Administration [63]. Additionally, these clinical trials are restricted to only the highest ranking Chinese hospitals. And perhaps most importantly, clinical patients may no longer be profited from, crippling the for-profit stem cell industry [63]. 


\section{Media-Hyped Magic Bullet Image of Stem Cell Therapy}

Unlike traditional treatments, stem cell therapies are not routinely recommended or advertised by doctors. Because of this gap in doctor-to-patient advertisement, the expanding media culture has filled this void by connecting patients with stem cell clinics in lieu of physicians. The media has served two influential roles: as a propagator of information - both substantiated and exaggerated - on stem cell therapy and as a convenient means of establishing clinic-to-patient relationships. The first and most obvious media outlet utilized by stem cell clinics are websites, often times reporting miraculous testimonials and inflated claims of treatment efficacy [61]. Additionally, the term "clinical trial" is often used liberally on these websites, giving the veneer of legitimacy which is associated with regulated clinical trials [61]. Many of these websites encourage medical tourism as well, pandering specifically to international patients and offering guidance and accommodations for their travel [64]. In a systematic review of US stem cell clinic websites, it was found that most diseases which the clinic advertised to treat had little-to-no scientific backing when searching the PubMed database [65]. These websites are central to the discussion, with nearly 8 million Americans searching for medical advice online daily [65]. Equally as important, due to current advertisement regulations, these websites may be the only way which clinics can directly connect to patients outside of the more undefined realm of social media outlets such as Twitter and Facebook [65].

Notwithstanding, media platforms, such as Twitter, are also significant factors affecting the public conception of stem cell therapy due to the overwhelmingly large transit of easily accessible online scientific information which can be disseminated to a massive audience base. Twitter presents a convenient and powerful tool to spread quasi-scientific reports and testimonials, having a significant impact on public opinion and perception. Two studies investigated the content of tweets on the subject of stem cells and found that the majority are positive or neutral in nature, with an underrepresentation of critical or skeptical viewpoints $[66,67]$. This poses a problem, as the use of unproven and unregulated treatment methods should indisputably be associated with healthy skepticism, yet biased media portrayal effects opinion and behavior. In the absence of healthy skepticism, and with the support of stem cell hype, terminally and chronically ill patients can understandably be drawn to unregulated stem cell clinics in hopes of finding the cure they desire.

In general, the Internet has become increasingly relevant to how patients view, become informed, and ultimately pursue their medical treatment under the banner of "nip, tuck, click" approach [68]. Trends such as third-party mediators and consultation services have aided in "removing the physician" from the medical process. One division of these internetbased services are those of stem cell clinic liaisons, who help to connect prospective patients with the clinic and mediate treatment plans [69]. As with the industry at large, these liaisons are not regulated, are not required to have any standardized training, and are not likely to present impartial adviceall of which puts the patient's safety in jeopardy [69].

\section{Effects of Unregulated Trials on the Scientific Field}

Unregulated stem cell therapies not only pose a risk to patients but also pose a wider danger to the scientific field of stem cell research as a whole. In addition to the patients who have paid large sums of money for ineffective treatments, a number of adverse events have been reported from stem cell therapies. A recent report of a glioproliferative spinal cord lesion highlights the dangers that are not only inherent with stem cell therapies but also those cells (e.g., cancer cells) which increase exponentially as the quality of stem cell treatments lessens [70]. The patient presented with a thoracic spinal and thecal sac tumor, which upon biopsy displayed predominantly of nonhost tissue [70]. Previously, the 66-year-old man had received intrathecal injections of mesenchymal, embryonic, and fetal neural stem cells from clinics in China, Argentina, and Mexico [70]. Current stem cell therapies hold a danger of over-proliferative lesions such as this, but the unregulated nature of these stem cell clinics means less well-defined cell types and a high risk of such growth.

Similarly, two cases of post-transplantation lesion formation have been described; one of a 46-year-old female who presented with an angiomyeloproliferative lesion found on her kidney after receiving intrarenal injection of stem cell for lupus nephritis from a Thailand clinic [71, 72]. Another case highlighted a Russian boy developing spinal and brain tumors following fetal stem cell transplants [71]. Other complications, such as blindness following ocular stem cell injections for macular degeneration, are not uncommon [58].

The development of such side effects is worrisome enough, but the true injustice lies in the inadequate warning patients receive prior to these unregulated stem cell procedures. As mentioned previously, the majority of stem cell clinics are hesitant to disclose the extent of the risks linked to their unapproved treatments. Accordingly, commercial stem cell clinics damage the reputation and integrity of stem cell therapy, tarnishing the actual potential that it holds [71]. These clinics and the risk of detrimental effects that they pose to unsuspecting patients impart skepticism upon the stem cell brand as a whole. With legislative bodies being instrumental in developing policies which harbor safe and effective stem cell developments, it is critical that the public opinion - composed of those who elect such legislators - remains critical of the unregulated clinics but favorable to the sound scientific evidence supporting stem cell research towards safe and effective therapies. The lessons of history tell us that public opinion may be easily influenced by a political machinery. 
Indeed, the effect of public and political opinion on stem cell research was exemplified during the Bush administration, with National Institutes of Health funding of embryonic stem cell research banned throughout the 8 years of presidency [53].

\section{Future Perspectives}

As the field of stem cell therapy moves forward, it is vital that the challenges presented above are addressed. The hazards of unregulated stem cell clinics must be tackled, as well as the regulatory hindrances which have plagued legitimate stem cell research. First and foremost, public education must be a priority, as a majority of the dangers posed by unregulated stem cell clinics depend on a degree of misinformation on the patient's part; misinformation is most effectively combatted by education. Ensuring that patients are well informed before deciding on stem cell therapies, as well as rooting out the myths and hype which surrounds stem cells, may have profound effects on curbing the growing stem cell clinic and medical tourism trends [73]. Educational resources already exist but are not widely available or utilized [73, 74]. Thus, making these resources more readily available and being proactive about educating patients following their diagnosis are important first steps. Instrumental to this will be ensuring that physicians and health care professionals prioritize patient education - especially in the case of traditionally incurable diseases such as multiple sclerosis, amyotrophic lateral sclerosis, and other chronic neurological diseaseand respect the patients' autonomy in the decision-making process, while also giving them the tools to make the safest choice.

The importance of cell therapy follow-up care should also be defined, including for example physical therapy and nursing care [75]. Because cell therapy treatments are recognized as risky within the medical field, patients may be hesitant to seek follow-up care after receiving such unadvised treatments. This only exacerbates the dangers though, as the patients are simultaneously undergoing a potentially dangerous treatment while also resistant to seek medical help [76]. In light of this, physicians should not only work to educate patients about the true risks of unproven stem cell therapies but also be careful not to stigmatize them to such a degree as to deter patients from maintaining an open line of communication if they do decide to undergo treatment [76].

A joint workshop held in 2013 by the Institute of Medicine, the National Academy of Sciences, and the International Society for Stem Cell Research explored the issues faced by the stem cell field and posed a number of important ideas [77]. Among these suggestions was that physicians should help patients sort through clinical trial options if they are determined to follow through with stem cell treatment plans. This approach requires that we maintain a realistic perspective on the likelihood that terminally ill patients who have proposed stem cell therapies are likely to pursue them. Thus, physicians may be able to promote patient safety by first discouraging the use of these experimental treatments and by also guiding patients to the most reputable and scientifically supported clinics if they are unwavering about their pursuit of this treatment [77]. This could be further improved by implementing a certification system for clinics, whereby clinics which subject themselves to additional regulations could be recognized for their transparency [77]. As an additional consequence, this may offer commercial incentives to clinics, with a higher safety rating encouraging patients to prefer one clinic over another.

Improved regulations by oversight institutions, such as the FDA, will also be critical in encouraging safe stem cell research and therapies. In order to both encourage the advancement of stem cell research, while also reigning in rogue stem cell clinics, cognizant legislation will certainly be necessary. Currently, the FDA has proposed a series of four draft guidelines and is considering public opinion before attempting to finalize the measures [77]. These guidelines will attempt to further distinguish legitimate clinical trials from clinics which use the façade of "research" as a marketing tool and pave the way for a more conducive atmosphere for the legitimate research bodies.

The case for the formation of a Stem Cell Ethics Consortium has been made previously [53]. An effective shift in stem cell policy and trajectory will require an open dialog and a well-designed consortium could serve as the platform for this much needed public discourse. Moreover, this would also allow for an interdisciplinary approach to solving the ethical, legal, and social issues which must be overcome if the promise of stem cell therapy is to be fully realized [53]. Undoubtedly, evidence-based solutions weighing the risks against the benefits and delineating the hype from hope have been proposed for the challenges discussed above, and thus, the onus now falls on us, the scientific community, and regulatory institutions to make meaningful changes towards the realization of safe and effective stem cell therapy for stroke.

\section{Conclusion}

Stem cell therapies are now recognized as a viable way to repair the brain following stroke and other neurological insults, but these cell-based therapies remain experimental. This comes as a result of laboratory findings which have advanced our understanding of how stem cells function and the practical differences of varying stem cell types; in particular, these findings have revealed MSCs as a leading candidate for 
stroke treatment. Importantly, MSCs maintain the ability to differentiate towards neural cell lineages and secrete growth and anti-inflammatory factors and are relatively convenient to harvest, circumventing many logistical as well as ethical concerns. Thus, MSCs and their derivatives have been heavily investigated in multiple US clinical trials and hold great promise as a source of stem cell-based clinical therapies. Clinical trials with MSCs and other cell types have unanimously agreed upon the safety of stem cell treatments, yet have been less conclusive on their efficacy for stroke. The reasons for this are not singular, but FDA policies which have been implemented in order to prioritize patient safety may also be inadvertently hindering the development of effective treatments. Additionally, technical factors, such as the innate complexity of stem cells, and a translational research disconnect between laboratory findings and clinical trial design have further slowed the process. Furthermore, the success of translational outcomes requires that we abandon the notion that stem cell therapy is a magic bullet for stroke and instead consider combining such therapy with gold standard of treatment of care, such as rehabilitation therapy and other emerging stroke therapeutics $[75,78-86]$ as well as being cognizant of stroke co-morbidities [87-92].

Beginning with their initial characterization, stem cells have been a source of great hope for patients suffering with debilitating disorders. In many cases though, this hope has led to a degree of scientifically unsubstantiated hype. This hype, paired with the delayed transition of stem cells into the clinic and vague regulatory guidelines, has created an atmosphere permitting the rise of commercial experimental stem cell clinics in the USA and abroad. These clinics pose a threat to patients who are often exploited and misinformed about the potential risks. Of equal importance, these clinics have the potential to negatively affect public opinion of stem cell therapies. When considering the legislative reforms which will be necessary to advance stem cell therapies to their full clinical promise, favorable public opinion is invaluable. The necessary reforms should address both the growing concern of unregulated stem cell clinics and the current limitations on valid research which have slowed the progression of stem cell therapies.

In addition to legislative changes, prioritizing patient education will be a key step in promoting patient safety and awareness of experimental stem cell clinics. Particularly upon diagnosis, ensuring that patients are fully aware of the stem cell option and the risk/benefit profile increases the likelihood that patients will make an informed decision about their treatment. Finally, creating an open dialog by forming an appropriate platform - specifically, a stem cell consortium - where an interdisciplinary approach can be pursued towards addressing the legal, ethical, and scientific issues will ultimately enhance the safety and efficacy of stem cell therapy for stroke in the clinic.
Acknowledgments CVB is funded by NIH R01NS071956, NIH R01 NS090962, NIH R21NS089851, NIH R21 NS094087, DOD W81XWH11-1-0634, VA Merit Review I01 BX001407, SanBio Inc., KMPHC, Karyopharm, International Stem Cell Corporation, and NeuralStem Inc.

\section{Compliance with Ethical Standards}

Conflict of Interest CVB received research grants from NIH, NeuralStem, Karyopharm, and SanBio Inc. and has patent applications related to stem cell therapy with Athersys Inc. and SanBio Inc. MGL and MGC declare that they have no conflict of interest.

Ethics Approval This article does not contain any studies with human participants or animals performed by any of the authors.

\section{References}

1. Muotri AR, Gage FH. Generation of neuronal variability and complexity. Nature. 2006;441(7097):1087-93. doi:10.1038 /nature04959.

2. Lindvall O, Kokaia Z. Stem cells for the treatment of neurological disorders. Nature. 2006;441(7097):1094-6. doi:10.1038 /nature04960.

3. Chen J, Venkat P, Zacharek A, Chopp M. Neurorestorative therapy for stroke. Front Hum Neurosci. 2014;8:382. doi:10.3389 /fnhum.2014.00382.

4. Boltze J, Lukomska B, Jolkkonen J, consortium M-I. Mesenchymal stromal cells in stroke: improvement of motor recovery or functional compensation? Journal of Cerebral Blood Flow and Metabolism: official journal of the International Society of Cerebral Blood Flow and Metabolism. 2014;34(8):1420-1. doi:10.1038/jcbfm.2014.94.

5. Borlongan CV. Age of PISCES: stem-cell clinical trials in stroke. Lancet. 2016;388(10046):736-8. doi:10.1016/S0140-6736(16 31259-4.

6. Stroemer P, Patel S, Hope A, Oliveira C, Pollock K, Sinden J. The neural stem cell line CTX0E03 promotes behavioral recovery and endogenous neurogenesis after experimental stroke in a dosedependent fashion. Neurorehabil Neural Repair. 2009;23(9):895909. doi:10.1177/1545968309335978.

7. Hara K, Yasuhara T, Maki M, Matsukawa N, Masuda T, Yu SJ, et al. Neural progenitor NT2N cell lines from teratocarcinoma for transplantation therapy in stroke. Prog Neurobiol. 2008;85(3):31834. doi:10.1016/j.pneurobio.2008.04.005.

8. Kaneko Y, Hayashi T, Yu S, Tajiri N, Bae EC, Solomita MA, et al. Human amniotic epithelial cells express melatonin receptor MT1, but not melatonin receptor MT2: a new perspective to neuroprotection. J Pineal Res. 2011;50(3):272-80. doi:10.1111/j.1600-079 X.2010.00837.x.

9. Liu SP, Fu RH, Wu DC, Hsu CY, Chang CH, Lee W, et al. Mouseinduced pluripotent stem cells generated under hypoxic conditions in the absence of viral infection and oncogenic factors and used for ischemic stroke therapy. Stem Cells Dev. 2014;23(4):421-33. doi: 10.1089/scd.2013.0182.

10. Li Z, McKercher SR, Cui J, Nie Z, Soussou W, Roberts AJ, et al. Myocyte enhancer factor $2 \mathrm{C}$ as a neurogenic and antiapoptotic transcription factor in murine embryonic stem cells. The Journal of Neuroscience: the official journal of the Society for Neuroscience. 2008;28(26):6557-68. doi:10.1523 /JNEUROSCI.0134-08.2008.

11. Borlongan CV, Glover LE, Tajiri N, Kaneko Y, Freeman TB. The great migration of bone marrow-derived stem cells toward the ischemic brain: therapeutic implications for stroke and other 
neurological disorders. Prog Neurobiol. 2011;95(2):213-28. doi:10.1016/j.pneurobio.2011.08.005.

12. Steinberg GK, Kondziolka D, Wechsler LR, Lunsford LD, Coburn ML, Billigen JB, et al. Clinical outcomes of transplanted modified bone marrow-derived mesenchymal stem cells in stroke: a phase 1/ 2a study. Stroke; a journal of cerebral circulation. 2016;47(7):181724. doi:10.1161/STROKEAHA.116.012995.

13. Prasad K, Sharma A, Garg A, Mohanty S, Bhatnagar S, Johri S, et al. Intravenous autologous bone marrow mononuclear stem cell therapy for ischemic stroke: a multicentric, randomized trial. Stroke; a journal of cerebral circulation. 2014;45(12):3618-24. doi:10.1161/STROKEAHA.114.007028.

14. Borlongan CV, Lind JG, Dillon-Carter O, Yu G, Hadman M, Cheng $\mathrm{C}$, et al. Intracerebral xenografts of mouse bone marrow cells in adult rats facilitate restoration of cerebral blood flow and bloodbrain barrier. Brain Res. 2004;1009(1-2):26-33. doi:10.1016/j. brainres.2004.02.050.

15. Acosta SA, Tajiri N, Hoover J, Kaneko Y, Borlongan CV. Intravenous bone marrow stem cell grafts preferentially migrate to spleen and abrogate chronic inflammation in stroke. Stroke; a journal of cerebral circulation. 2015;46(9):2616-27. doi:10.1161 /STROKEAHA.115.009854.

16. Savitz SI, Cramer SC, Wechsler L, Consortium S. Stem cells as an emerging paradigm in stroke 3: enhancing the development of clinical trials. Stroke; a journal of cerebral circulation. 2014;45(2):6349. doi:10.1161/STROKEAHA.113.003379.

17. Savitz SI, Chopp M, Deans R, Carmichael T, Phinney D, Wechsler $\mathrm{L}$, et al. Stem cell therapy as an emerging paradigm for stroke (STEPS) II. Stroke; a journal of cerebral circulation. 2011;42(3): 825-9. doi:10.1161/STROKEAHA.110.601914.

18. Borlongan CV, Fournier C, Stahl CE, Yu G, Xu L, Matsukawa N, et al. Gene therapy, cell transplantation and stroke. Frontiers in bioscience: a journal and virtual library. 2006;11:1090-101.

19. Lo B, Parham L. Ethical issues in stem cell research. Endocr Rev. 2009;30(3):204-13. doi:10.1210/er.2008-0031.

20. Tang Y, Yasuhara T, Hara K, Matsukawa N, Maki M, Yu G, et al. Transplantation of bone marrow-derived stem cells: a promising therapy for stroke. Cell Transplant. 2007;16(2):159-69.

21. Gnecchi M, Melo LG. Bone marrow-derived mesenchymal stem cells: isolation, expansion, characterization, viral transduction, and production of conditioned medium. Methods Mol Biol. 2009;482: 281-94. doi:10.1007/978-1-59745-060-7_18.

22. Maria Ferri AL, Bersano A, Lisini D, Boncoraglio G, Frigerio S, Parati E. Mesenchymal stem cells for ischemic stroke: progress and possibilities. Curr Med Chem. 2016;23(16):1598-608.

23. Yasuhara T, Matsukawa N, Hara K, Maki M, Ali MM, Yu SJ, et al. Notch-induced rat and human bone marrow stromal cell grafts reduce ischemic cell loss and ameliorate behavioral deficits in chronic stroke animals. Stem Cells Dev. 2009;18(10):1501-14. doi:10.1089 /scd.2009.0011.

24. Yasuhara T, Hara K, Maki M, Mays RW, Deans RJ, Hess DC, et al. Intravenous grafts recapitulate the neurorestoration afforded by intracerebrally delivered multipotent adult progenitor cells in neonatal hypoxic-ischemic rats. Journal of Cerebral Blood Flow and Metabolism: official journal of the International Society of Cerebral Blood Flow and Metabolism. 2008;28(11):1804-10. doi:10.1038/jcbfm.2008.68.

25. Uchida H, Morita T, Niizuma K, Kushida Y, Kuroda Y, Wakao S, et al. Transplantation of unique subpopulation of fibroblasts, muse cells, ameliorates experimental stroke possibly via robust neuronal differentiation. Stem Cells. 2016;34(1):160-73. doi:10.1002 /stem.2206.

26. Borlongan CV. Bone marrow stem cell mobilization in stroke: a 'bonehead' may be good after all! Leukemia. 2011;25(11):167486. doi:10.1038/leu.2011.167.
27. Rowart P, Erpicum P, Detry O, Weekers L, Gregoire C, Lechanteur $\mathrm{C}$, et al. Mesenchymal stromal cell therapy in ischemia/reperfusion injury. Journal of Immunology Research. 2015;2015:602597. doi:10.1155/2015/602597.

28. Eckert MA, Vu Q, Xie K, Yu J, Liao W, Cramer SC, et al. Evidence for high translational potential of mesenchymal stromal cell therapy to improve recovery from ischemic stroke. Journal of Cerebral Blood Flow and Metabolism: official journal of the International Society of Cerebral Blood Flow and Metabolism. 2013;33(9): 1322-34. doi:10.1038/jcbfm.2013.91.

29. Kocsis JD, Honmou O. Bone marrow stem cells in experimental stroke. Prog Brain Res. 2012;201:79-98. doi:10.1016/B978-0-44459544-7.00005-6.

30. Joyce N, Annett G, Wirthlin L, Olson S, Bauer G, Nolta JA. Mesenchymal stem cells for the treatment of neurodegenerative disease. Regen Med. 2010;5(6):933-46. doi:10.2217/rme.10.72.

31. van Velthoven CT, Gonzalez F, Vexler ZS, Ferriero DM. Stem cells for neonatal stroke - the future is here. Front Cell Neurosci. 2014;8: 207. doi:10.3389/fncel.2014.00207.

32. Anderson JD, Johansson HJ, Graham CS, Vesterlund M, Pham MT, Bramlett CS, et al. Comprehensive proteomic analysis of mesenchymal stem cell exosomes reveals modulation of angiogenesis via nuclear factor-kappaB signaling. Stem Cells. 2016;34(3):601-13. doi:10.1002/stem.2298.

33. Duffy GP, Ahsan T, O'Brien T, Barry F, Nerem RM. Bone marrowderived mesenchymal stem cells promote angiogenic processes in a time- and dose-dependent manner in vitro. Tissue Eng A. 2009;15(9):2459-70. doi:10.1089/ten.TEA.2008.0341.

34. Xiong Y, Mahmood A, Chopp M. Angiogenesis, neurogenesis and brain recovery of function following injury. Curr Opin Investig Drugs. 2010;11(3):298-308.

35. Ishikawa H, Tajiri N, Shinozuka K, Vasconcellos J, Kaneko Y, Lee HJ, et al. Vasculogenesis in experimental stroke after human cerebral endothelial cell transplantation. Stroke; a journal of cerebral circulation. 2013;44(12):3473-81. doi:10.1161 /STROKEAHA.113.001943.

36. Schweizer S, Meisel A, Marschenz S. Epigenetic mechanisms in cerebral ischemia. Journal of Cerebral Blood Flow and Metabolism: official journal of the International Society of Cerebral Blood Flow and Metabolism. 2013;33(9):1335-46. doi:10.1038/jcbfm.2013.93.

37. Puyal J, Ginet V, Clarke PG. Multiple interacting cell death mechanisms in the mediation of excitotoxicity and ischemic brain damage: a challenge for neuroprotection. Prog Neurobiol. 2013;105: 24-48. doi:10.1016/j.pneurobio.2013.03.002.

38. Sozmen EG, Hinman JD, Carmichael ST. Models that matter: white matter stroke models. Neurotherapeutics: the journal of the American Society for Experimental NeuroTherapeutics. 2012;9(2):349-58. doi:10.1007/s13311-012-0106-0.

39. Kim SJ, Moon GJ, Chang WH, Kim YH, Bang OY, collaborators S. Intravenous transplantation of mesenchymal stem cells preconditioned with early phase stroke serum: current evidence and study protocol for a randomized trial. Trials. 2013;14:317. doi:10.1186/1745-6215-14-317.

40. Surder D, Radrizzani M, Turchetto L, Cicero VL, Soncin S, Muzzarelli S, et al. Combined delivery of bone marrow-derived mononuclear cells in chronic ischemic heart disease: rationale and study design. Clin Cardiol. 2013;36(8):435-41. doi:10.1002 /clc.22148.

41. Prasad K, Mohanty S, Bhatia R, Srivastava MV, Garg A, Srivastava $\mathrm{A}$, et al. Autologous intravenous bone marrow mononuclear cell therapy for patients with subacute ischaemic stroke: a pilot study. Indian J Med Res. 2012;136(2):221-8.

42. Mackie AR, Losordo DW. CD34-positive stem cells: in the treatment of heart and vascular disease in human beings. Tex Heart Inst J. 2011;38(5):474-85. 
43. Kalladka D, Sinden J, Pollock K, Haig C, McLean J, Smith W, et al. Human neural stem cells in patients with chronic ischaemic stroke (PISCES): a phase 1, first-in-man study. Lancet. 2016;388(10046): 787-96. doi:10.1016/S0140-6736(16)30513-X.

44. Savitz SI, Misra V, Kasam M, Juneja H, Cox Jr CS, Alderman S, et al. Intravenous autologous bone marrow mononuclear cells for ischemic stroke. Ann Neurol. 2011;70(1):59-69. doi:10.1002 /ana.22458.

45. Banerjee S, Bentley P, Hamady M, Marley S, Davis J, Shlebak A, et al. Intra-arterial immunoselected CD34+ stem cells for acute ischemic stroke. Stem Cell Transl Med. 2014;3(11):1322-30. doi:10.5966/sctm.2013-0178.

46. Bang OY, Lee JS, Lee PH, Lee G. Autologous mesenchymal stem cell transplantation in stroke patients. Ann Neurol. 2005;57(6):874 82. doi:10.1002/ana.20501.

47. Pollock K, Stroemer P, Patel S, Stevanato L, Hope A, Miljan E, et al. A conditionally immortal clonal stem cell line from human cortical neuroepithelium for the treatment of ischemic stroke. Exp Neurol. 2006;199(1):143-55. doi:10.1016/j. expneurol.2005.12.011.

48. Sibbald B. Death but one unintended consequence of gene-therapy trial. CMAJ. 2001;164(11):1612.

49. Stevanato L, Corteling RL, Stroemer P, Hope A, Heward J, Miljan EA, et al. c-MycERTAM transgene silencing in a genetically modified human neural stem cell line implanted into MCAo rodent brain. BMC Neurosci. 2009;10:86-98. doi:10.1186/1471-220210-86.

50. Dao MA, Tate CC, Aizman I, McGrogan M, Case CC. Comparing the immunosuppressive potency of naive marrow stromal cells and Notch-transfected marrow stromal cells. J Neuroinflammation. 2011;8:133-47. doi:10.1186/1742-2094-8-133.

51. Napoli E, Borlongan CV. Recent advances in stem cell-based therapeutics for stroke. Transl Stroke Res. 2016;7(6):452-7. doi:10.1007/s12975-016-0490-6.

52. Diamandis $\mathrm{T}$, Borlongan $\mathrm{CV}$. One, two, three steps toward cell therapy for stroke. Stroke; a journal of cerebral circulation. 2015;46(2):588-91. doi:10.1161/STROKEAHA.114.007105.

53. Borlongan CV, McWhirter C, Fultz-Carver C, Fitzgerald KT, Sanberg PR. The case for an ethics research consortium for emerging technologies: public perception of stem cell research and development. Technology and Innovation. 2010;12:21-8.

54. Hyun I. Therapeutic hope, spiritual distress, and the problem of stem cell tourism. Cell Stem Cell. 2013;12(5):505-7. doi:10.1016 /j.stem.2013.04.010.

55. McArdle A, Senarath-Yapa K, Walmsley GG, Hu M, Atashroo DA, Tevlin R, et al. The role of stem cells in aesthetic surgery: fact or fiction? Plast Reconstr Surg. 2014;134(2):193-200. doi:10.1097 /PRS.0000000000000404.

56. Ryan KA, Sanders AN, Wang DD, Levine AD. Tracking the rise of stem cell tourism. Regen Med. 2010;5(1):27-33. doi:10.2217 /rme.09.70.

57. Turner L. US stem cell clinics, patient safety, and the FDA. Trends Mol Med. 2015;21(5):271-3. doi:10.1016/j.molmed.2015.02.008.

58. Ledford H. Boom in unproven cell therapies intensifies regulatory debate. Nature. 2016;537(7619):148. doi:10.1038/537148a.

59. Cyranoski D. Stem cells in Texas: cowboy culture. Nature. 2013;494(7436):166-8. doi:10.1038/494166a.

60. Brown C. Stem cell tourism poses risks. CMAJ. 2012;184(2): E121-2. doi:10.1503/cmaj.109-4073.

61. McLean AK, Stewart C, Kerridge I. Untested, unproven, and unethical: the promotion and provision of autologous stem cell therapies in Australia. Stem Cell Research \& Therapy. 2015;6:33. doi:10.1186/s13287-015-0047-810.1186/scrt543.

62. Cyranoski D. China's stem-cell rules go unheeded. Nature. 2012;484(7393):149-50. doi:10.1038/484149a.
63. Rosemann A, Sleeboom-Faulkner M. New regulation for clinical stem cell research in China: expected impact and challenges for implementation. Regen Med. 2016;11(1):5-9. doi:10.2217 /rme.15.80.

64. Mason A, Wright KB. Framing medical tourism: an examination of appeal, risk, convalescence, accreditation, and interactivity in medical tourism web sites. J Health Commun. 2011;16(2):163-77. doi: $10.1080 / 10810730.2010 .535105$.

65. Lau D, Ogbogu U, Taylor B, Stafinski T, Menon D, Caulfield T. Stem cell clinics online: the direct-to-consumer portrayal of stem cell medicine. Cell Stem Cell. 2008;3(6):591-4. doi:10.1016/j. stem.2008.11.001.

66. Kamenova K, Reshef A, Caulfield T. Representations of stem cell clinics on Twitter. Stem Cell Rev. 2014;10(6):753-60. doi:10.1007 /s12015-014-9534-z.

67. Robillard JM, Cabral E, Hennessey C, Kwon BK, Illes J. Fueling hope: stem cells in social media. Stem Cell Rev. 2015;11(4):540-6. doi:10.1007/s12015-015-9591-y.

68. Lunt N, Hardey M, Mannion R. Nip, tuck and click: medical tourism and the emergence of web-based health information. The Open Medical Informatics Journal. 2010;4:1-11. doi:10.2174 /1874431101004010001.

69. Wagle S. Web-based medical facilitators in medical tourism: the third party in decision-making. Indian Journal of Medical Ethics. 2013;10(1):28-33.

70. Berkowitz AL, Miller MB, Mir SA, Cagney D, Chavakula V, Guleria I, et al. Glioproliferative lesion of the spinal cord as a complication of "stem-cell tourism". N Engl J Med. 2016;375(2): 196-8. doi:10.1056/NEJMc1600188.

71. Cyranoski D. Strange lesions after stem-cell therapy. Nature. 2010;465(7301):997. doi:10.1038/465997a.

72. Thirabanjasak D, Tantiwongse K, Thorner PS. Angiomyeloproliferative lesions following autologous stem cell therapy. Journal of the American Society of Nephrology: JASN. 2010;21(7):1218-22. doi:10.1681/ASN.2009111156.

73. Master Z, Robertson K, Frederick D, Rachul C, Caulfield T. Stem cell tourism and public education: the missing elements. Cell Stem Cell. 2014;15(3):267-70. doi:10.1016/j.stem.2014.08.009.

74. Tsou A. Ethical considerations when counseling patients about stem cell tourism. Continuum. 2015;21(1 Spinal Cord Disorders):201-5. doi:10.1212/01.CON.0000461094.76563.be.

75. Ploughman M, Austin MW, Glynn L, Corbett D. The effects of poststroke aerobic exercise on neuroplasticity: a systematic review of animal and clinical studies. Transl Stroke Res. 2015;6(1):13-28. doi:10.1007/s12975-014-0357-7.

76. Eissler LA, Casken J. Seeking health care through international medical tourism. Journal of Nursing Scholarship: an official publication of Sigma Theta Tau International Honor Society of Nursing. 2013;45(2):177-84. doi:10.1111/jnu.12014.

77. Stem cell therapies: opportunities for ensuring the quality and safety of clinical offerings - summary of a joint workshop. Washington (DC) 2014.

78. Merali Z, Leung J, Mikulis D, Silver F, Kassner A. Longitudinal assessment of imatinib's effect on the blood-brain barrier after ischemia/reperfusion injury with permeability MRI. Transl Stroke Res. 2015;6(1):39-49. doi:10.1007/s12975-014-0358-6.

79. Zhu W, Casper A, Libal NL, Murphy SJ, Bodhankar S, Offner H, et al. Preclinical evaluation of recombinant $\mathrm{T}$ cell receptor ligand RTL1000 as a therapeutic agent in ischemic stroke. Transl Stroke Res. 2015;6(1):60-8. doi:10.1007/s12975-014-0373-7.

80. Khan MB, Hoda MN, Vaibhav K, Giri S, Wang P, Waller JL, et al. Remote ischemic postconditioning: harnessing endogenous protection in a murine model of vascular cognitive impairment. Transl Stroke Res. 2015;6(1):69-77. doi:10.1007/s12975-014-0374-6.

81. Kandadai MA, Meunier JM, Hart K, Holland CK, Shaw GJ. Plasmin-loaded echogenic liposomes for ultrasound-mediated 
thrombolysis. Transl Stroke Res. 2015;6(1):78-87. doi:10.1007 /s12975-014-0376-4.

82. Shi Y, Leak RK, Keep RF, Chen J. Translational stroke research on blood-brain barrier damage: challenges, perspectives, and goals. Transl Stroke Res. 2016;7(2):89-92. doi:10.1007/s12975-0160447-9.

83. Lioutas VA, Alfaro-Martinez F, Bedoya F, Chung CC, Pimentel DA, Novak V. Intranasal insulin and insulin-like growth factor 1 as neuroprotectants in acute ischemic stroke. Transl Stroke Res. 2015;6(4):264-75. doi:10.1007/s12975-015-0409-7.

84. Morihara R, Kono S, Sato K, Hishikawa N, Ohta Y, Yamashita T, et al. Thrombolysis with low-dose tissue plasminogen activator 3$4.5 \mathrm{~h}$ after acute ischemic stroke in five hospital groups in Japan. Transl Stroke Res. 2016;7(2):111-9. doi:10.1007/s12975-0160448-8.

85. Reuter B, Rodemer C, Grudzenski S, Meairs S, Bugert P, Hennerici MG, et al. Effect of simvastatin on MMPs and TIMPs in human brain endothelial cells and experimental stroke. Transl Stroke Res. 2015;6(2):156-9. doi:10.1007/s12975-014-0381-7.

86. Soliman S, Ishrat T, Fouda AY, Patel A, Pillai B, Fagan SC. Sequential therapy with minocycline and candesartan improves long-term recovery after experimental stroke. Transl Stroke Res. 2015;6(4):309-22. doi:10.1007/s12975-015-0408-8.

87. Ergul A, Hafez S, Fouda A, Fagan SC. Impact of comorbidities on acute injury and recovery in preclinical stroke research: focus on hypertension and diabetes. Transl Stroke Res. 2016;7(4):248-60. doi:10.1007/s12975-016-0464-8.

88. Hasegawa Y, Nakagawa T, Uekawa K, Ma M, Lin B, Kusaka H, et al. Therapy with the combination of amlodipine and irbesartan has persistent preventative effects on stroke onset associated with BDNF preservation on cerebral vessels in hypertensive rats. Transl Stroke Res. 2016;7(1):79-87. doi:10.1007/s12975-014-0383-5.

89. McCann SK, Cramond F, Macleod MR, Sena ES. Systematic review and meta-analysis of the efficacy of interleukin-1 receptor antagonist in animal models of stroke: an update. Transl Stroke Res. 2016;7(5):395-406. doi:10.1007/s12975-016-0489-z.

90. Sun N, Keep RF, Hua Y, Xi G. Critical role of the sphingolipid pathway in stroke: a review of current utility and potential therapeutic targets. Transl Stroke Res. 2016;7(5):420-38. doi:10.1007 /s12975-016-0477-3.

91. Suzuki H, Shiba M, Nakatsuka Y, Nakano F, Nishikawa H. Higher cerebrospinal fluid $\mathrm{pH}$ may contribute to the development of delayed cerebral ischemia after aneurysmal subarachnoid hemorrhage. Transl Stroke Res. 2016; doi:10.1007/s12975-016-0500-8.

92. Yigitkanli K, Zheng Y, Pekcec A, Lo EH, van Leyen K. Increased 12/15-lipoxygenase leads to widespread brain injury following global cerebral ischemia. Transl Stroke Res. 2016; doi:10.1007 /s12975-016-0509-z. 